\title{
A importância da documentação e da descrição linguística para a revitalização de línguas ameaçadas
}

\author{
The importance of linguistic documentation and description for revitalization of \\ endangered languages
}

\author{
Bruna Fernanda S. de Lima Padovani* \\ Camille Cardoso Miranda ${ }^{* *}$ \\ Jeanne Barros de Barros ${ }^{* * *}$
}

\begin{abstract}
RESUMO: Pesquisas linguísticas que visam à documentação e à descrição são de extrema importância para a revitalização de línguas ameaçadas. São estudos que beneficiam as comunidades, fortalecendo suas línguas e culturas e auxiliando também no conhecimento científico dessas comunidades. Este artigo faz uma breve reflexão acerca da importância da documentação e da descrição para a revitalização de línguas que estão ameaçadas de extinção. São apresentados, ainda, exemplos de ações de valorização e de revitalização da língua Apurinã (Aruák), falada no sudoeste do estado do Amazonas. Discutem-se tais fatores com vistas à promoção da valorização das línguas e culturas indígenas do Brasil.
\end{abstract}

PALAVRAS-CHAVE: Documentação. Descrição. Revitalização. Línguas Indígenas.

\begin{abstract}
Researches projects aiming at documenting and describing endangered languages are extremely important for their revitalization. In addition, to promoting scientific knowledge, such studies also benefit the linguistic communities, by contributing to strengthen their languages and cultures. This paper offers a brief reflection on the importance of language description and documentation for the revitalization of languages threatened by extinction, focusing on efforts aimed at the promotion and revitalization of Apurinã, an Aruák language spoken in the southwest of the Brazilian state of Amazonas. The paper then discusses such examples as they relate to the general issue of promoting the strengthening of Brazil's indigenous languages and cultures.
\end{abstract}

KEYWORDS:

Documentation.

Descriptions. Revizalization. Indigenous Languages.

\footnotetext{
* Doutoranda em Estudos Linguísticos pelo programa de Pós-Graduação em Letras da Universidade Federal do Pará. E-mail: bflimapadovani@gmail.com

${ }^{* *}$ Doutoranda em Linguística pelo Instituto de Estudos da Linguagem (IEL) da Universidade Estadual de Campinas. E-mail: camiranda126@gmail.com

*** Mestra em Estudos Linguísticos pelo programa de Pós-Graduação em Letras da Universidade Federal do Pará. E-mail: jeannebarrosufpa@yahoo.com.br
} 


\section{Introdução}

A diversidade linguística que existe no mundo é inestimável, intimamente conectada com a diversidade cultural e os conhecimentos tradicionais. Conforme o consenso de vários linguistas (cf. AUSTIN; SALLABANK, 2011, p. 1), há aproximadamente 7 mil línguas faladas no mundo. Contudo, destas, uma grande parcela está gravemente ameaçada de extinção (AUSTIN; SALLABANK, 2011). É urgente que se trabalhe contra essa perda, ajudando comunidades linguísticas a manter suas línguas tradicionais por meio, por exemplo, de trabalhos linguísticos e educacionais, e/ou documentando-as o máximo possível, enquanto são ativamente usadas ou lembradas. A tabela abaixo apresenta o número de línguas que correm alto risco desaparecer por áreas geográficas do mundo:

Tabela 01 - Línguas em perigo de extinção' ${ }^{1}$.

\begin{tabular}{c|c} 
Área & Número \\
\hline África & 131 \\
\hline Américas & 339 \\
\hline Ásia & 187 \\
\hline Europa & 51 \\
\hline Pacífico & 208 \\
\hline Total & 916
\end{tabular}

Fonte: Ethnologue ${ }^{2}$

Em relação à diversidade linguística específica do Brasil, de acordo com os últimos dados do IBGE $(2010)^{3}$, a população indígena é de aproximadamente 897 mil pessoas, compondo 305 etnias. São faladas cerca de 274 línguas por aproximadamente 37,4\% do total de indígenas. Rodrigues (2013) registra 199 delas, enquanto Moore et al.

\footnotetext{
${ }^{1}$ Incluindo as línguas moribundas. Línguas em que os únicos falantes ativos são membros de gerações dos avós ou mais idosos.

${ }_{2}^{2}$ Informações mais detalhadas no site: https://www.ethnologue.com.

${ }^{3}$ Disponível em: https://censo2010.ibge.gov.br/noticias-censo?busca=1\&id=3\&idnoticia=2194\&t=censo2010-poblacao-indigena-896-9-mil-tem-305-etnias-fala-274\&view=noticia.
} 
(2008, p. 38) afirmam que, pelo critério de inteligibilidade mútua, a soma dificilmente ultrapassaria 150.

É importante ressaltar que o grau de perigo de extinção de línguas indígenas foi subestimado por anos no Brasil, devido à confusão entre número de falantes vs. população do grupo, somando a isso as distintas variedades de uma língua que eram consideradas como uma língua distinta.

Dados sobre a transmissão das línguas são ainda mais difíceis de se conseguir, mas é o principal determinante do futuro delas. De acordo com Moore e Galucio (2016), 21\% das 150 línguas faladas no Brasil apresentam um alto grau de perigo de extinção em um futuro próximo por causa do baixo número de falantes e da falta de transmissão. Facundes et al. (2018) apresentam um levantamento preliminar das línguas indígenas da Amazônia brasileira, classificadas em diferentes graus de vitalidade, como se pode observar no mapa abaixo. Segundo Facundes et al. (2018), esse mapa seria muito mais complexo se as variedades de cada uma dessas línguas fossem nele representadas. 
Figura 1 - Estado das Línguas Indígenas Amazônicas (FACUNDES et al., 2018)4.
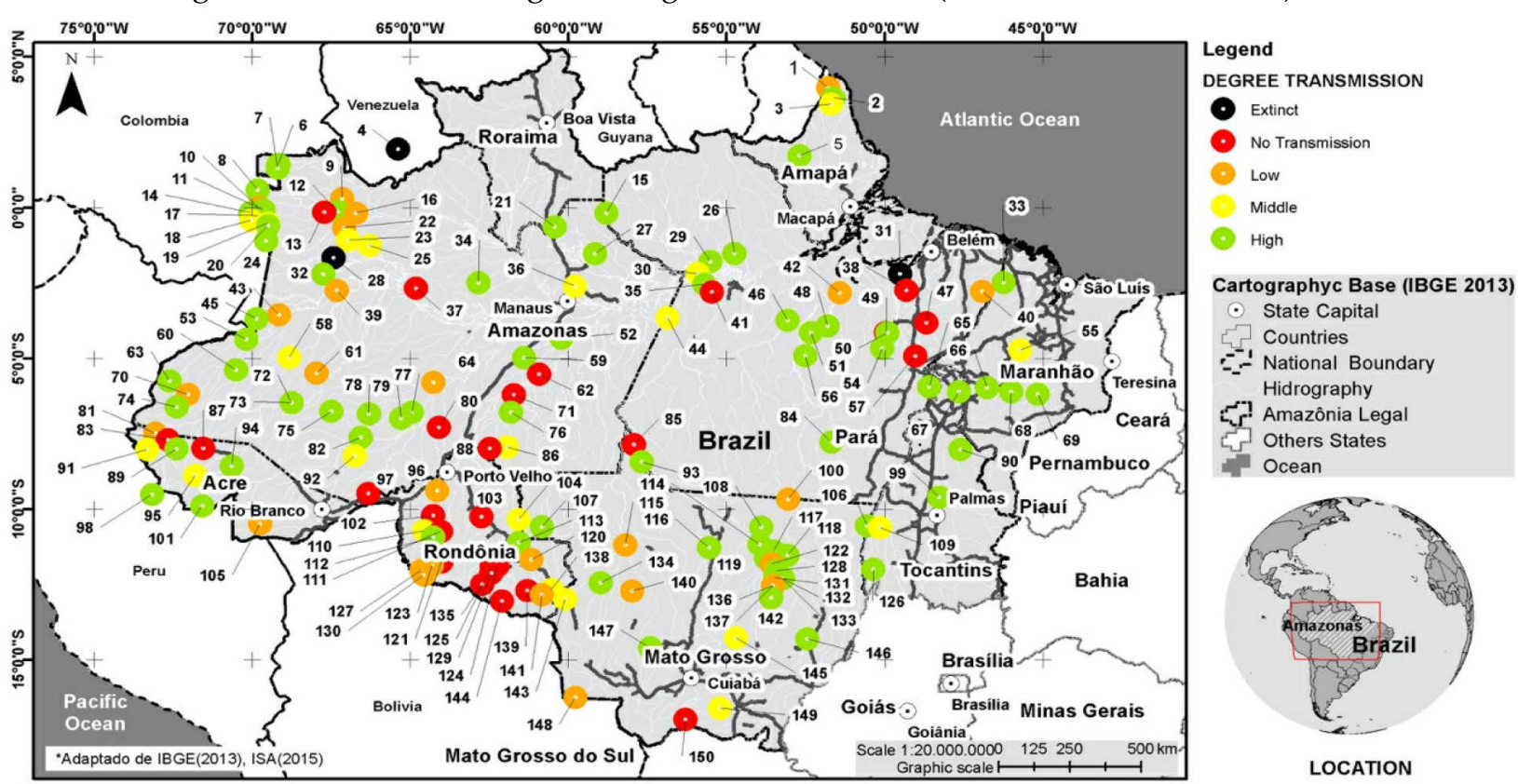

Fonte: Facundes et al. (2018)

A redução do número de línguas indígenas é um processo devastador e violento que se perpetua até os dias de hoje. Conforme Austin e Sallabank (2011), aquelas que

${ }^{4} 1$ Galibi; 2 Palikur; 3 Karipuna of Amapá; 4 Baré; 5 Wajampi; 6 Sirionó; 7 Kubeo; 8 Hupda; 9 Baré; 10 Barasano; 11 Karapaná; 12 Dãw; 13 Arapasso; 14 Macuna (Yebá-masã); 15 Hixkaryana; 16 Tariana; 17 Yuhup; 18 Tuyuca; 19 Waikana; 20 Desano; 21 Waimiri-Atroari; 22 Warekena; 23 Nheengatú; 24 Kotiria (Wanáno); 25 Nadëb; 26 Apalaí; 27 Wai wai; 28 Kaixana; 29 Zo'é; 30 Kaxuyana; 31 Turiwára; 32 Baníwa; 33 Ka'apor; 34 Yanomami; 35 Tiriyó; 36 Wapishana; 37 Muinane; 38 Anambé; 39 Kokáma; 40 Tembé; 41 Wayana; 42 Krenák; 43 Kambeba (Kokama); 44 Sataré -Mawé; 45 Tikuna; 46 Arara; 47 Amanayé; 48 Galibi Maworno; 49 Xipáya; 50 Asuriní do Tocantins; 51 Asuriní do Xingu; 52 Macuxí; 53 Matsis; 54 Parakanã; 55 Guajajára/Tenetehara; 56Araweté; 57 Gavião Parkatejé and Kykateyé; 58 Ingariko; 59 Taurepang (Pemóng); 60 Korúbo; 61Tosohon-dyapa; 62 Mura; 63 Matses; 64 Paumarí; 65 Suruí of Tocantins; 66 Krinkatí; 67 Apinajé; 68 Canela Apaniekrã; 69 Canela Ramkokamekrã; 70 Kulina; 71Torá; 72 Kanamarí; 73 Katukina de Biá; 74 Marubo; 75 Dení; 76 Pirahã; 77 Banawá; 78 Suruwaha; 79 Jarawara; 80 Juma; 81 Poyanáwa; 82 Jamamadi; 83 Nawa; 84 Kayapó (Mebêngôkrê); 85 Apiaká; 86 Tenharím; 87 Arara (Shawãdawa); 88 Jiahui; 89 Katukina do Acre; 90 Krahô; 91 Shanenawa; 92 Apurinã; 93 Mundurukú; 94 Kulina; 95 Yawanawa; 96 Karitiána; 97 Kaxarari; 98 Ashaninka; 99 Xerénte; 100 Terena; 101Yaminawa (Jamináwa); 102 Karipuna; 103 Urupá; 104 Káro (Arara); 105 Maxinéri; 106 Tapirapé; 107 Cinta-Larga; 108 Panará; 109 Avá-Canoeiro; 110 Wari'; 111 Oro Win; 112 Uru-eu-wau-wau (kawahib); 113 Suruí Paiter; 114 Tapayuna; 115 Rikbaktsá; 116 Kayabí; 117 Ikpeng; 118 Kisidjê (Suyá); 119 Nahukwa; 120 Kwaza; 121 Kujubim; 122 Trumai; 123 Makurap; 124 Tupari; 125 Puruborá; 126 Karajá; 177 Jeoromitxi; 128 Matipu; 129 Aruá; 130 Kanoé; 131 Kamayurá; 132 Kuikúru; 133 Kalapalo; 134 Enawenê-nawê/Salumâ; 135 Arikapú; 136 Mehinaku; 137 Yawalapití; 138 Aikaná; 139 Wayoró; 140 Irantxe; 141 Akuntsú; 142 Awetí; 143 Nambiquara; 144 Mekéns; 145 Bakairí; 146 Xavánte; 147 Paresí; 148 Chiriguiano; 149 Boróro; 150 Guató (FACUNDES et al., 2018). 
estão ameaçadas têm passado por mudanças nos seus perfis, pois muitas são faladas apenas por pessoas mais velhas, e os jovens tipicamente estão apresentando um processo de mudança linguística (language shift) em que acabam utilizando mais as línguas majoritárias, por exemplo, o português, no caso do Brasil, do que a sua língua nativa. Essa situação torna-se cada vez mais crítica, pois, como mencionamos anteriormente, coloca muitas línguas em uma situação de perda linguística bastante avançada.

Como apontou Seki (1999), as línguas indígenas recebem diferentes pressões. O impacto com populações envolventes ou línguas majoritárias afeta cada vez mais não apenas a situação linguística brasileira, como também aspectos socioculturais. A autora, conforme assinalava há vinte anos, desconhecia a existência de um levantamento geral que pudesse estabelecer com maior exatidão os reflexos do impacto do português em distintos grupos indígenas, tanto no que diz respeito a graus de bilinguismo quanto no que se refere às interferências do português nessas línguas. Esse contato não é tão perceptível nas primeiras fases, mas aos poucos vai se consolidando e afetando as línguas minoritárias (SEKI, 1991).

Essa mudança traz consequências significativas na estrutura linguística das línguas minoritárias, uma vez que elas acabam sofrendo alterações lexicais ou gramaticais devido às influências das línguas francas. De acordo com Mühlhäusler (1996), as línguas da região do Pacífico, por exemplo, apresentaram mudanças tipológicas por conta do contato com línguas europeias. Essas línguas, anteriormente, tinham a tendência de ter um tipo morfológico de síntese, mas, em virtude do contato com a língua majoritária, elas, atualmente, estão apresentando um perfil tipológico de línguas fusionais (flexionais), que é uma tendência morfológica das línguas europeias. Além da perda do tipo morfológico, essas línguas também perderam aspectos de concordância gramatical. 
Mühlhäusler (1996) explica que essas mudanças estão deixando essas línguas menos complexas morfologicamente, e que traços como a polissíntese estão desaparecendo do Pacífico. Assim, segundo o autor, as distinções que poderiam ser feitas em estágios anteriores não são mais realizados por falantes mais jovens. Isso acarreta um impacto na manutenção dessas línguas, já que os falantes, frequentemente os das gerações mais novas, estão alterando seus sistemas estruturais em decorrência de outras estruturas que não fazem parte da gramática deles.

Para Mühlhäusler (1996), é importante mencionar que línguas extintas ou que já apresentam estruturas modernizadas, ou seja, com itens lexicais ou gramaticais que não faziam parte do repertório linguístico dos falantes, mas que agora já se internalizaram, apresentam o mesmo efeito. Isto é, os falantes acabam empregando as categorias gramaticais e semânticas de línguas majoritárias, e o nível linguístico dessas línguas acaba sendo substituído por variações específicas, por exemplo, a mudança de ordem de palavras, questões relacionadas à morfologia verbal, convergência lexical com línguas francas etc. Essa mudança na estrutura linguística, em uma perspectiva ecológica, incide também na estrutura social e cultural desses povos.

Mufwene (2001), ao refletir sobre a diversidade linguística e fatores sociolinguísticos relativos ao desaparecimento de línguas, afirma que elas são enfraquecidas, entre outros fatores, quando é alterada sua função e seus domínios de uso, ou seja, quando se modifica seu status, tornando restrito o uso de determinadas línguas ao mesmo passo em que é ampliado o uso de outras (majoritárias). O caso de países que passaram por processos de colonização ilustra essas alterações, uma vez que foram estabelecidas nesses países políticas linguísticas voltadas para a manipulação dos usos das línguas nas quais línguas ou variedades de línguas foram oficializadas para a educação e administração do país e, posteriormente, foram implementadas ações de ensino dessas línguas. Essas ações são fundamentadas em ideologias homogeneizadoras que concebiam a diversidade linguística e cultural como 
empecilho aos interesses do Estado, como no caso do Brasil, em que a construção de sua identidade nacional tem como base políticas de enfraquecimento linguístico e cultural destinadas a seus povos originários.

Um grande número de línguas indígenas, como já mencionamos anteriormente, corre também perigo de desaparecer rapidamente devido ao número extremamente reduzido de falantes e à não transmissão para as novas gerações, o que também prejudica o conhecimento científico dessas línguas. Conforme Moore et al. (2008), as línguas mais ameaçadas são também as menos estudadas ou documentadas.

Portanto, trabalhos de descrição, documentação e revitalização de línguas minoritárias são de suma importância, não apenas para a ampliação de estudos linguísticos, mas também para a preservação de saberes socioculturais e de estruturas linguísticas que estão se perdendo em razão do processo de obsolescência que muitas línguas indígenas brasileiras vêm passando há décadas. Diante da importância dos estudos de documentação e descrição para a revitalização de línguas ameaçadas de extinção, o presente artigo tem o objetivo de apresentar algumas considerações sobre tais aspectos, destacando fatores das práticas linguísticas como determinantes para o processo de revitalização.

O artigo está organizado em quatro seções, além desta introdução. Na primeira, apresentamos uma visão geral acerca da descrição e documentação linguística; na segunda, discutimos sobre a tarefa de revitalização linguística de línguas ameaçadas de extinção; na terceira, são apresentados exemplos de ações de valorização e revitalização linguística de uma língua indígena no sudoeste do estado do Amazonas (Apurinã); e, por fim, são feitas algumas considerações gerais sobre a relevância e contribuição de trabalhos de descrição e documentação para a revitalização linguística. 


\section{Visão geral sobre descrição e documentação linguística}

Duas ações bastante importantes na revitalização de línguas são a descrição e a documentação linguística. Essas atividades vão se diferenciar em termos dos seus objetivos, contudo ambas as técnicas são bastante complementares, podendo os pesquisadores trabalhar em conjunto. A subseção abaixo descreve algumas considerações sobre a documentação linguística.

\subsection{Documentação linguística}

Conforme Woodbury (2011), a documentação linguística tem como objetivo: “a criação, anotação, preservação e divulgação de registros transparentes de uma língua" (WOODBURY, 2011, p. 159) e é um processo que deve ser acelerado, ampliado, popularizado e transformado (WOODBURY, 2011). Cada vez mais, as comunidades estão procurando documentar os aspectos linguísticos utilizados em diferentes práticas discursivas (ex. rituais, canções tradicionais, narrativas orais etc.).

Para Himmelmann (2006, p. 1), a documentação linguística é: “um registro duradouro e polivalente de um idioma". Conforme esse autor, os dados primários que constituem a documentação de uma língua incluem gravações de áudios e de vídeos de um evento comunicativo, elicitações ou transcrições. Esses dados primários devem ser organizados em um corpus estruturado e que possa ser acessível para vários tipos de anotações e comentários (HIMMELMANN, 2006).

Segundo Austin (2010), a documentação linguística desenvolveu-se cada vez mais nos últimos anos por conta da necessidade de se obter um registro duradouro das diferentes línguas ameaçadas no mundo. O estudo também auxilia os falantes dessas línguas no desejo da manutenção de sua língua materna. Himmelmann (2006) explica que a documentação não é apenas uma área de interesse da Linguística, mas também de outras áreas como Arqueologia, Antropologia e História. Desse modo, compreendemos que a documentação linguística é, por natureza, multidisciplinar, e, 
como observa Woodbury (2011), baseia-se nos conceitos e técnicas tanto da Linguística, quanto da Etnografia, da Psicologia, da Ciência da Computação etc.

Woodbury (2011) afirma que os propósitos da documentação podem ter várias finalidades. Nesse sentido, a documentação não é apenas destinada à revitalização de línguas, mas também à reconstrução histórica, social e ideológica relacionada à manutenção das identidades culturais. Desse modo, deve ser adaptada conforme os interesses das comunidades a quem ela se destina.

Para Himmelmann (2006), a documentação linguística se preocupa principalmente com a organização e a preservação dos dados primários da língua e com a interface desses dados com outros tipos de análise. Assim sendo, o autor (HIMMELMANN, 2006, p. 15) identifica cinco características importantes na documentação linguística:

- foco nos dados primários - a documentação linguística se preocupa com a coleta e análise de uma matriz de dados linguísticos para que sejam disponibilizados para uma ampla gama de usuários;

- responsabilidade - deve-se acessar os dados primários e as suas representações, realizando evolução de análises linguísticas possíveis e esperadas;

- preocupação com o armazenamento a longo prazo e com a preservação de dados primários - a documentação linguística inclui um foco no arquivamento, a fim de garantir que materiais documentais da língua sejam disponíveis para futuras gerações;

- trabalho interdisciplinar - a documentação requer informações e conhecimento de uma série de disciplinas e não se restringe à linguística;

- cooperação e envolvimento direto da comunidade da fala - a documentação requer um trabalho ativo e colaborativo com os membros da comunidade, tanto como produtores de materiais da língua quanto como copesquisadores.

À medida que os projetos de documentação linguística são iniciados, registros e anotações sobre o seu progresso se tornam disponíveis e seus resultados são depositados em arquivos de mídias (AUSTIN, 2010). Drude (2006), a propósito, afirma 
que apesar da grande perda da diversidade linguística no mundo sua documentação teve um grande avanço graças às novas tecnologias, como gravações de áudio e de vídeos que possibilitaram realizar registros de alta qualidade em trabalhos de campo nas comunidades onde a língua é falada diariamente. Os programas computacionais especializados também auxiliam na criação de acervos digitais. Himmelmann (2006, p. 11) afirma que a documentação como um todo necessita incluir nos arquivos informações de dados secundários que são os metadados, acompanhados com as seguintes informações:

- nomes dos participantes que estão sendo gravados;

- quem fez os registros e para qual finalidade;

- local e data do registro;

- qual o equipamento utilizado;

- quem é público-alvo;

- uma breve caracterização do conteúdo que está sendo discutido.

Segundo as informações de Himmelmann (2006), existem dois padrões de metadados que complementam um ao outro. O primeiro padrão é $\mathrm{Olac}^{5}$, que visa exclusivamente à função de catalogação e fornece um acesso rápido a um grande número de arquivos de dados primários em uma escala mundial. O segundo padrão é o Imdi ${ }^{6}$, o qual incorpora todos os dados do Olac e, portanto, é compatível com ele. Esse programa é uma ferramenta de gerenciamento de corpus que visa principalmente à documentação de línguas arquivadas digitalmente (HIMMELMANN, 2006).

Além desses metadados, é importante mencionar os programas linguísticos que auxiliam na organização, na documentação e na análise dos dados primários. Por exemplo, para dividir o sinal de áudio em segmentos que correspondem mais ou menos à sentença da fala, podemos utilizar o transcriber. Esse programa suporta

\footnotetext{
${ }^{5}$ Informações mais detalhadas pelo site: http://www.olacinc.org/.

${ }^{6}$ Informações mais detalhadas pelo site: https://tla.mpi.nl/imdi-metadata/.
} 
múltiplas camadas hierárquicas de segmentação de forma que podem ser vistas simultaneamente duas formas de onda sonora em diferentes resoluções, além de suportar várias codificações de caracteres, incluindo Unicode e as fontes do IPA (Alfabeto Fonético Internacional).

Um outro programa bastante utilizado para organização e análise dos registros realizados em trabalhos de campo é o FLEx (FieldWorks Language Explorer). O programa oferece ao linguista a opção de criar um banco de dados de acordo com as especificidades do trabalho de pesquisa. Ele abrange várias opções, como: a inserção de textos e a interlinearização deles; frases; palavras; morfemas; transcrição fonética; som; referências cruzadas; informações fonológicas, morfológicas e sintáticas; variações; etimologia; notas culturais e antropológicas; discurso; informações gramaticais, semânticas e sociolinguísticas; informações enciclopédicas e científicas; detalhes da coleta de dados como a fonte de informação; local e data da coleta; nome do participante, e outras funções que permitem ao pesquisador a realização completa de um banco de dados detalhado, visando também à documentação dos dados da língua. O programa também permite a convergência com outros programas computacionais como o ELAN (The Language Archive) ${ }^{7}$ e o Lexique Pro ${ }^{8}$, e ainda oferece a opção de exportar arquivos em PDF.

Assim sendo, podemos compreender que a documentação linguística é um mecanismo importante na preservação de línguas e culturas. De acordo com Austin (2010), existem quatro razões para a documentação ser um campo que cresceu dentro

\footnotetext{
${ }^{7}$ O Elan é um programa computacional de distribuição gratuita produzido pelo Instituto Max Planck (https://tla.mpi.nl/tools/tla-tools/elan/download/). Essa ferramenta é utilizada para anotar e transcrever, manual e semiautomaticamente, gravações de áudio ou vídeo.

${ }^{8}$ O Lexique Pro é um visualizador e editor de léxico interativo, de distribuição gratuita, produzido pelo International Society of Linguistic (http://www.lexiquepro.com), com hiperlinks entre as entradas, exibições de categorias, reversão de dicionário, pesquisa e ferramentas de exportação. Ele é projetado para exibir os dados em um formato de fácil acesso para que possa ser compartilhado com outros pesquisadores. Esse programa pode ler e exibir um banco de dados lexical se for: (i) um arquivo de texto com marcadores de formato padrão reconhecidos (como dados produzidos pelo Toolbox), ou (ii) um arquivo XML no formato LIFT (produzido pela FLEx).
} 
da Linguística. A primeira é a preocupação de linguistas e de outros pesquisadores com a situação crítica de uma grande parcela das línguas do mundo que, consequentemente, ameaça a diversidade linguística. A segunda razão é o interesse dos linguistas em pesquisas teóricas e tipológicas na incorporação de dados de um número amplo de línguas que podem não ser geneticamente relacionadas, para realizar diferentes análises, comparar e verificar os padrões e as tendências universais para um estudo tipológico das línguas do mundo. A terceira é olhar a língua não como um sistema abstrato, mas sim como um uso social. A última razão é o surgimento de financiamentos de agências governamentais preocupadas em documentar línguas ameaçadas.

Por fim, a documentação é um passo importante na revitalização de uma língua. Com esse estudo, é possível realizar decisões de planejamentos linguísticos, coletar dados para diferentes finalidades, elaborar materiais digitais como vídeos em formatos de DVD e/ou de Cds de áudios registrando alguma prática tradicional bastante importante para comunidade. O estudo também auxilia na análise de teorias linguísticas (fonéticas, fonológicas, morfossintáticas, lexicais, semânticas e entre outras) e é uma etapa fundamental para o conhecimento científico das línguas do mundo.

A subseção seguinte traz considerações gerais sobre a descrição linguística.

\subsection{Descrição linguística}

Antes de iniciarmos a discussão sobre alguns conceitos básicos da descrição linguística, é importante compreender que a documentação linguística não é uma descrição linguística. Austin (2010) argumenta que muitos pesquisadores sugeriram que a documentação linguística é uma descrição praticada por muitos estudiosos no início do século XX, com adição de tecnologias de áudio digital e gravação de vídeo. 
Para o autor (2010, p. 14), isso é "uma deturpação que falha no sentido da análise dos aspectos da documentação linguística que diferenciam-se da descrição".

De acordo com Austin (2010), a documentação e descrição linguística diferem em termos dos seus objetos, áreas de interesse, métodos de pesquisa, fluxos de trabalho e resultados. Himmelmann (1998) explica que a tarefa de registrar uma língua pouco conhecida compreende duas atividades: coleta, transcrição e tradução dos dados primários e uma análise descritiva deles. Assim como Austin (2010), o autor também alega que a documentação e a descrição são substancialmente diferentes no que diz respeito aos métodos empregados, como também nos resultados obtidos. Segundo Himmelmann (1998), a descrição linguística é, em geral, útil para pesquisadores que se direcionam a trabalhar com gramáticas ou comparações de línguas.

Portanto, a descrição linguística tipicamente objetiva à produção de gramáticas, dicionários e coleção de textos, e o público-alvo, geralmente, são os linguistas ou os estudiosos da área. Austin elucida que embora a descrição se baseie em um corpus, ela envolve uma análise de ordem diferente, ou seja, a descrição abrange uma compreensão da língua em um nível mais abstrato, como um sistema de elementos, regras e construções fonológicas, morfossintáticas e semânticas (AUSTIN, 2010).

Podemos compreender, então, que, diferentemente da documentação linguística que não visa apenas registrar aspectos linguísticos, mas que também abrange diversidade das línguas em diferentes contextos socioculturais, o estudo da descrição tem um interesse maior nas análises dos dados, com a finalidade de descrever ou apresentar uma gramática (descritiva) e um dicionário. Essas atividades são tipicamente linguísticas. O quadro 1, abaixo, adaptado de Himmelmann (1998), resume algumas diferenças entre documentação e descrição. 
Quadro 1 - Diferenças entre a documentação e descrição linguística.

\begin{tabular}{|l|l|l|}
\hline \multirow{4}{*}{ Resultados } & Documentação & Descrição \\
\hline \multirow{3}{*}{ Procedimentos } & $\begin{array}{l}\text { Corpus de enunciados, notas } \\
\text { sobre observações e } \\
\text { comentários feitos pelos } \\
\text { falantes, registros arquivados } \\
\text { em acervos digitais etc. }\end{array}$ & $\begin{array}{l}\text { Gramáticas, dicionários, } \\
\text { coleção de textos. }\end{array}$ \\
\hline $\begin{array}{l}\text { Observações dos } \\
\text { participantes, elicitações, } \\
\text { gravações, transcrições e } \\
\text { traduções dos dados } \\
\text { primários. }\end{array}$ & $\begin{array}{l}\text { Análise fonética, } \\
\text { fonológica, } \\
\text { morfossintática e } \\
\text { semântica. }\end{array}$ \\
\hline metodológicas & $\begin{array}{l}\text { Amostragem, finalidades, } \\
\text { para quem se destina, os tipos } \\
\text { de equipamentos, local e } \\
\text { data... }\end{array}$ & $\begin{array}{l}\text { Definição de termos e } \\
\text { níveis, justificação } \\
\text { (adequada) da análise. }\end{array}$ \\
\hline
\end{tabular}

Fonte: Himmelmann (1998, p. 5).

Na subseção que segue, trataremos brevemente da documentação e da descrição em línguas indígenas brasileiras.

\subsection{Documentação e descrição em línguas indígenas brasileiras}

Atualmente, programas de documentação e trabalhos de descrição linguística das línguas indígenas brasileiras têm aumentado. Vários projetos internacionais prontificaram-se a auxiliar a documentação de línguas indígenas ameaçadas. São eles: o DOBES (Documentação de Línguas Ameaçadas), da Alemanha, e o ELDP (Programa de Documentação de Línguas Ameaçadas), da Inglaterra. De acordo com a informação de Moore et al. (2008), esses programas já apoiaram a documentação de 19 línguas brasileiras. Outros programas importantes que também visam à documentação são: EMELD (Electronic Metastructure for Endangered Languages Datas), AILLA (The Archive of the Indigenous Languages of Latina America) e ELF (Endangered Languages Fund). 
Em relação aos programas de documentação realizados por fundações brasileiras, podemos mencionar o Prodclin ${ }^{9}$ (Programa de Documentação de Línguas Indígenas), que foi criado em 2009 pela Fundação Nacional do Índio (Funai), pela Fundação Banco do Brasil e pela Unesco, por intermédio do Museu do Índio. Esse projeto visa à preservação do patrimônio cultural e linguístico dos povos indígenas brasileiros e promove o acesso para futuras gerações desses povos e também para pesquisadores interessados em trabalhar com a documentação e a descrição das línguas indígenas brasileiras. De acordo com as informações do site do Prodclin, até o momento, o trabalho de documentação está sendo realizado em 13 línguas indígenas que foram escolhidas pelo critério de graus de ameaça. As línguas que participam do projeto são: Apiaká, Desano, Haliti-Paresí, Kaiabi-Kawaiete, Kanoé, Kisêdjê, Karajá, Maxakali, Ikpeng, Ninam, Rikbaktsa, Shawãdawa e Yawanawa.

Os estudos descritivos sobre essas línguas tiveram um aumento significativo e estão cada vez mais disponíveis ao público em geral (SILVA, 2009). Tais pesquisas podem ser encontradas em forma de livros, gramáticas, dicionários, coleções de textos, teses, dissertações, periódicos e capítulos de livros. Os eventos acadêmicos também cooperam na elaboração de publicações referentes aos vários estudos de línguas indígenas faladas no Brasil, ajudando na circulação dos conhecimentos científicos sobre esses povos. Por fim, não podemos deixar de citar o site etnolinguistica ${ }^{10}$, que fornece um banco de dados condensado com diferentes trabalhos acadêmicos e documentos etnográficos das línguas indígenas do Brasil e dos países vizinhos.

Em suma, é possível compreender que, apesar da situação extremamente preocupante das línguas indígenas brasileiras, nos últimos anos, muitos pesquisadores têm se dedicado profundamente a documentar e a descrever essas línguas. Contudo,

\footnotetext{
${ }^{9}$ Endereço do projeto Prodclin: http://prodoclin.museudoindio.gov.br/

${ }^{10}$ Endereço do site: http://www.etnolinguistica.org/
} 
muitas etapas ainda precisam ser realizadas, principalmente no planejamento de revitalização linguística, aspecto tratado na próxima seção.

\section{Revitalização linguística}

O contato entre populações de diferentes línguas e culturas vem delineando, ao longo da história das sociedades, comportamentos linguísticos e configurando o que conhecemos por diversidade linguística. A diversidade linguística não abrange somente o reconhecimento das diferentes línguas existentes e faladas em todo o mundo, como também as formas diferentes de uso dessas línguas (práticas linguísticas).

Do contato entre línguas e culturas, fatores histórico-sociais, como os econômicos, a dominação cultural e os processos de colonização determinam mudanças linguísticas. Entre as consequências desses processos está o abandono de línguas em relação ao uso majoritário de outras, o que culmina no processo de extinção de algumas delas. Esse último implica perdas significativas de conhecimentos científicos relacionados à natureza e ao funcionamento da linguagem, uma vez que, quando as línguas desaparecem, deixamos de conhecer sistemas linguísticos únicos.

Não menos importante que a supressão do conhecimento científico, o processo de extinção impõe aos povos falantes de línguas minoritárias mudanças e perdas, totais ou parciais, de sua identidade cultural. Alicerçados no entendimento de que essas perdas são extremamente negativas à livre manifestação cultural desses povos e à diversidade linguística, ferindo o direito de eles serem quem são e de falarem suas línguas, que estudiosos de diversas áreas e organizações representantes dessas populações passaram a buscar a revitalização e a manutenção de suas línguas e culturas.

A tarefa de revitalização das línguas ameaçadas de extinção consiste, de maneira geral, no desenvolvimento de ações que objetivam trazê-las, novamente, ao 
nível de utilização dentro de suas comunidades e que encontram, essencialmente na transmissão das línguas para as gerações futuras, chances reais para o não desaparecimento delas (HINTON, 2001). O desenvolvimento dessas ações implica um processo minucioso de compreensão da função, dos usos, das relações entre as línguas e do que querem os falantes em relação à sua língua nativa para então formular estratégias voltadas à manutenção dos usos (contextos de usos) em suas comunidades.

Para Spolsky (2004), o entendimento das práticas linguísticas, das relações sociais, ideológicas e das crenças presentes nas relações entre as línguas e as sociedades - fatores esses que Schiffman (1996) determina como um sistema de regras e práticas chamado "cultura linguística" - é fundamental, uma vez que são tais fatores (sistema) que determinam a transmissão/ensino ou não das línguas, ou seja, que determinam os contextos de uso/desuso e status das línguas, ao mesmo passo que também determinam o desenvolvimento de ações de revitalização possivelmente mais eficazes. Portanto, as ações, as estratégias e os métodos para a revitalização de línguas devem considerar aspectos da cultura e da prática linguística que vigoram nas sociedades por serem os falantes agentes cujas práticas conduzem o trabalho linguístico.

No contexto brasileiro, nos últimos trinta anos, muito se discute e trabalha em favor dos povos e das línguas indígenas, resultado da organização desses povos na busca pelos direitos das populações minoritárias, pelo direito à língua e à cultura. No entanto, apesar dos esforços, muito ainda é preciso fazer para que o enfraquecimento e o desaparecimento de línguas indígenas brasileiras sejam, de fato, uma preocupação política e social. As iniciativas de revitalização das línguas indígenas brasileiras se tornaram mais fortes com o reconhecimento delas como línguas presentes e faladas em território brasileiro a partir da constituição de 1988.

Desde essa mudança de status, muitas línguas indígenas foram documentadas e descritas, e também iniciados os processos de ensino-aprendizagem que objetivam o seu não desaparecimento. Nesse contexto, as escolas nas comunidades indígenas 
aparecem como lugar para a valorização da diversidade linguística e cultural (CUNHA, 2008). No entanto também são celeiros de grandes e importantes discussões, principalmente acerca das metodologias utilizadas e das finalidades da alfabetização em língua portuguesa e em língua materna. Porém o mais importante nessas discussões é considerar as relações entre as línguas no desenvolvimento de toda ação que busque incentivar contextos de usos para que elas sejam faladas (LADEIRA, 2016).

A escola, o ensino formal, a alfabetização em línguas minoritárias não são os únicos meios para a revitalização linguística, existem outras formas de buscar usos dessas línguas d (ver MOORE; GABAS JÚNIOR, “O Futuro das Línguas Indígenas Brasileiras"). Porém, em muitos casos, é o meio mais importante para tal tarefa, pois, entre outros argumentos, fomenta o prestígio e a utilidade das línguas, despertando o interesse por elas nas gerações mais jovens. $\mathrm{O}$ ensino das línguas indígenas brasileiras em contextos escolares (ou mais regulares) conta com o trabalho da documentação e da descrição, em especial na elaboração de materiais didáticos.

O desenvolvimento de alfabetos, cadernos com atividades de escrita na língua indígena ou materiais que envolvem pronúncia, que podem ou não tomar a língua portuguesa como referência, são fundamentalmente realizados com a participação dos falantes, uma vez que as ações de revitalização que buscam resultados mais eficientes devem dar aos falantes o papel principal. A contribuição do trabalho de documentação e descrição está em levar para o contexto de ensino da língua não somente seu sistema, mas seus fatores de variação e seus contextos de uso, para que alcancem o objetivo, a funcionalidade e a ampliação desses contextos.

Na seção que segue, apresentaremos alguns exemplos de ações de valorização e revitalização linguística de uma língua indígena no sudoeste do estado do Amazonas (Apurinã). 


\section{Experiências de revitalização no sudoeste do Amazonas}

A língua Apurinã é uma de cerca de 40 representantes da família linguística Aruák, que permanecem vivas (AIKHENVALD, 2005). Essa língua é falada pelo povo de mesmo nome, em comunidades espalhadas às margens de vários afluentes do rio Purus, no sudeste do estado do Amazonas e em comunidades ao longo da rodovia 317, que liga as cidades de Rio Branco e Boca do Acre. Há também um número bastante significativo de apurinãs vivendo fora das aldeias, principalmente nas periferias das cidades de Rio Branco (AC), Boca do Acre (AM), Pauini (AM), Lábrea (AM), Canutama (AM), Tapauá (AM), Manacapuru (AM) e Manaus (AM). Além disso, há alguns Apurinã vivendo em terras indígenas de outras etnias, sendo duas com os Paumari nos lagos Paricá e Marahã, uma com a etnia Jamamadi do Lourdes e uma com os índios Torá, na terra de mesmo nome no município de Manicoré (AM), e com etnias Tupí, em Rondônia (FACUNDES, 2000).

Atualmente, a população Apurinã conta com aproximadamente 6.842 pessoas (IBGE, 2010 ${ }^{11}$ distribuídas em dezenas de comunidades. A língua é falada por possivelmente $30 \%$ da população, com diferentes graus de fluência. Parte dos Apurinã é bilíngue, sendo que o português é a língua principal na maioria das comunidades. Essas comunidades, por sua vez, possuem graus diferentes de bilinguismo, algumas usando quase que exclusivamente o português nas interações do dia a dia, e uma minoria mantendo a comunicação na língua nativa de seu grupo. Diante desse quadro, podemos concluir que Apurinã é uma língua ameaçada de extinção, pois somente uma parcela da população ainda a utiliza. Em geral, somente os mais idosos são considerados falantes fluentes; os jovens apenas compreendem ou sabem parte do

11 Censo Demográfico 2010, com base no quesito cor ou raça. Disponível em: http://www.funai.gov.br/arquivos/conteudo/ascom/2015/img/05-Dez/pdf-brasil-ind.pdf. Acesso em: 15 mar. 2018. 
léxico; as crianças, em sua maioria, não aprendem mais o Apurinã como sua primeira língua (LIMA-PADOVANI, 2016).

Lima-Padovani (2016) classifica as diferentes realidades sociolinguísticas desse povo em quatro grupos:

- grupos majoritariamente monolíngues em Apurinã;

- grupos bilíngues em que a língua Apurinã ainda é produtiva, sendo usada nas atividades diárias, nas reuniões internas da aldeia e nos rituais;

- grupos em que o Apurinã é usado somente pelos mais velhos;

- grupos em que língua Apurinã foi praticamente substituída pela língua portuguesa, sendo que a maioria ou até todas as pessoas pertencentes a tais grupos não conhecem quase nada de sua língua nativa.

Dentro desse contexto, tem havido algumas atitudes que visam estimular o uso da língua indígena em detrimento do português. Uma delas, intitulada "Eu sou bilíngue intercultural"12, tem por objetivo revitalizar a língua e a cultura indígena. Entretanto as atividades resultantes dessa iniciativa se restringem apenas a dois encontros semanais, e não têm por objetivo formar professores na língua, acontecendo apenas na cidade de Lábrea e não nas comunidades indígenas, portanto contemplando apenas os que já migraram para a cidade.

Há também a produção de diversos materiais didáticos voltados para o ensino da língua13. São eles: (i) um livro voltado para a alfabetização, intitulado "Hamu ayutsopatary iie Pupỹkary Sãkire" (Escrevendo em Apurinã); (ii) um livro de conversação "Amu asãkirewata Pupỹkary Sãkire" (Vamos conversar na língua Apurinã); (iii) um livro com apenas atividades relacionadas ao livro de conversação, em que se deu atenção às diversas variedades linguísticas presentes na língua (ver LIMA-PADOVANI, 2016);

\footnotetext{
${ }^{12} \mathrm{O}$ projeto "Eu sou bilíngue intercultural" é uma iniciativa idealizada pelo povo Paumari (pertencente à família linguística Arawa) que se estendeu aos Apurinã.

13 Resultado de mais de trinta anos de trabalho do Prof. Dr. Sidi Facundes e de seus alunos da Universidade Federal do Pará.
} 
(iv) um dicionário de fauna e flora; (v) um dicionário geral bilíngue Apurinã/Português-Português/Apurinã, em fase de elaboração; e (vi) uma coletânea de narrativas tradicionais Apurinã. Todos esses materiais foram organizados pelo Prof. Dr. Sidi Facundes e sua equipe de alunos $^{14}$.

Como mencionamos anteriormente, as comunidades Apurinã estão distribuídas ao longo do rio Purus, apresentando grandes distâncias entre si, o que, por sua vez, gera uma enorme diversidade no que diz respeito à situação sociolinguística e cultural desse povo, bem como a relação que eles mantêm com a língua. Assim, é importante pontuar que, na concepção e elaboração dos materiais didáticos, levamos em consideração o status do Apurinã para as comunidades. Observamos que, na maioria das comunidades, a L1 é o português e a língua Apurinã possui status de língua do povo, dos pais, mas não do indivíduo, o qual mantém suas interações em português, mesmo em casa nas suas relações familiares. Nos casos mais graves, a língua Apurinã pode até ser considerada como língua estrangeira, pois o português é usado em família e em todas as interações sociais. Diante disso, concluímos que a maneira mais funcional para o ensino-aprendizagem do Apurinã seria a utilização do português como linguagem de instrução (ao menos em um estágio inicial). A razão disso é que o português é a L1 na maior parte das comunidades. Assim, o ensino de apurinã seguiria a metodologia de ensino de L2.

Vale frisar também que todos esses materiais foram produzidos em coautoria com os falantes Apurinã. Em conjunto, buscamos organizar e elaborar os materiais alinhando os critérios e os métodos indígenas e não indígenas com o intuito principal de fortalecer a identidade Apurinã. Desse modo, os materiais didáticos Apurinã representariam um "empoderamento" válido e sólido que tem o objetivo de trazer ao

\footnotetext{
${ }^{14}$ Equipe constituída inicialmente (além de Sidi Facundes) pela antropóloga Pirjo Kristiina Virtanen, Bruna de Lima-Padovani, Marília Freitas, Patricia Costa, Bianca Rodrigues, Laíse Barros e atualmente pela Rayssa Rodrigues, Alice Braga e Cinthia Ishida.
} 
protagonismo os falantes Apurinã calados pela assimetria da diglossia entre língua majoritária e minoritária.

Do ponto de vista prático, os materiais didáticos assegurarão o registro escrito, auxiliando o povo nos estudos de ensino-aprendizagem da sua língua nativa, bem como das suas distintas variedades linguísticas ${ }^{15}$, especialmente no que diz respeito ao desenvolvimento de letramento ${ }^{16}$ e de aquisição da escrita Apurinã.

Esperamos, ainda, que os materiais possam colaborar tanto como incentivo para os falantes Apurinã a refletirem sobre sua língua e sua cultura e valorizá-las quanto para incentivar os membros da sociedade majoritária (em especial, os indivíduos não indígenas que vivem na mesma região que esse povo) a conhecer melhor a riqueza da língua e da cultura dos Apurinã, proporcionando assim a quebra de preconceitos, a compreensão e a aceitação da diversidade cultural, bem como o desenvolvimento de atitudes de respeito mútuo.

Recentemente, houve nos municípios de Lábrea - AM (abril de 2015 e dezembro de 2016), Tapauá - AM (dezembro de 2016) e Boca do Acre - AM (julho de 2017) oficinas direcionadas aos professores e a algumas lideranças Apurinã, ministradas pelo Prof. Dr. Sidi Facundes e sua equipe de alunos sobre o ensino da língua Apurinã, onde foram apresentados os materiais supramencionados, discutida a ortografia e os aspectos gramaticais da língua, e apresentadas também propostas de atividades que os professores poderão desenvolver com seus alunos nas escolas Apurinã. Tais iniciativas marcam essa nova fase de revitalização da língua.

\footnotetext{
${ }^{15}$ Vale ressaltar que, na elaboração e organização dos materiais didáticos voltados para o ensino da língua Apurinã, teve-se o cuidado e a preocupação de contemplar suas distintas variedades linguísticas. Para tanto, foi realizado um levantamento sociolinguístico dessa língua esistematizadas as variedades no que concerne aos aspectos linguísticos (fonológico, morfológico e semântico) e extralinguísticos (geográfico e social - faixa etária e gênero (ver LIMA-PADOVANI, 2016).

${ }_{16}$ De acordo com os relatos dos falantes Apurinã, a alfabetização na sua língua nativa seria um importante processo de valorização e revitalização do Apurinã, uma vez que apenas $30 \%$ deles falam a língua com diferentes graus de bilinguismo.
} 
Vale ressaltar a atitude positiva dos participantes em relação a tudo o que foi discutido na oficina e aos usos da sua língua. Tal atitude nos permite perceber que a língua Apurinã passou a ganhar um status social mais elevado dentro da sociedade Apurinã, o que é bastante produtivo, pois esse tipo de relação com a língua pode contribuir positivamente para ampliar contextos de uso da língua nativa dentro da comunidade. Isso mostra o quanto o povo apurinã está interessado em lutar para manter a sua tradição linguística e cultural, mesmo diante da condição de dominação política da sociedade majoritária.

\section{Considerações finais}

O presente artigo apresentou alguns aspectos importantes relativos ao fortalecimento, ao conhecimento e à revitalização de línguas ameaçadas de extinção. Vimos que a documentação e a descrição linguística são etapas essenciais na revitalização e/ou manutenção de uma língua. $O$ fortalecimento desse elo entre documentação e descrição é fundamental para o êxito no processo de revitalização de uma língua.

Conforme Dalby (2003 apud DRUDE, 2006, p. 29), a perda da diversidade linguística é universal e a principal causa é a exploração e integração de áreas remotas. Nesse processo, Drude (2006, p. 23) elucida que as condições de vida dos grupos indígenas mudam drasticamente. Dentro dessas condições, encontra-se a "valorização" de línguas e culturas majoritárias acima das minoritárias, uma vez que muitos falantes (principalmente os mais jovens) deixam de utilizar sua língua materna substituindo-a pelo português, por exemplo. Por isso, programas como os descritos neste trabalho, que se prontifiquem a ajudar no fortalecimento e na valorização das línguas e culturas indígenas brasileiras, são de extrema importância.

Arquivos digitais que documentam os registros de trabalhos realizados em comunidades indígenas auxiliam na preservação e valorização do patrimônio cultural 
e linguístico existente no Brasil. Consequentemente, essas documentações também contribuem em trabalhos descritivos que auxiliam na elaboração de gramáticas, dicionários, textos e na circulação do conhecimento científico propiciados por elas. De acordo com Drude (2006, p. 30), as documentações linguísticas permitem que hipóteses e análises dos aspectos linguísticos sejam testadas e verificadas, até mesmo em línguas que já se encontram extintas. Para o autor, o processo documental é útil também nas atividades de fortalecimento ou revitalização de línguas e apoia procedimentos metodológicos que sirvam à difusão do uso e ensino delas.

Pudemos observar também, ao longo do trabalho, que a tarefa de revitalização implica o desenvolvimento de ações para o fortalecimento dos usos das línguas e, para tanto, é imprescindível a compreensão das relações entre as sociedades e as línguas, pois são elas que determinam de fato os usos/desusos (práticas linguísticas) e as possibilidades de transmissão/ensino das línguas, por serem fundamentadas na dimensão do que pensam e querem seus falantes.

Somando-se a esse processo, os trabalhos de documentação e descrição possibilitam o registro das línguas, o que é importante para as ações de revitalização por serem processos de longa duração com análises mais aprofundadas dos usos das línguas, permitindo também o desenvolvimento de materiais para um ensino próximo aos usos com vistas à potencialização dos contextos desses usos.

Vimos, ainda, exemplo de ações de valorização e revitalização desenvolvidas para a língua Apurinã. São elas: (i) o projeto intitulado "Eu sou bilíngue intercultural”, iniciativa dos próprios indígenas (idealizada pelo povo Paumari e posteriormente aderida pelos Apurinã); (ii) a produção de materiais didáticos voltados para alfabetização e conversação em Apurinã, além de dicionários e coletâneas de narrativas tradicionais Apurinã; (iii) oficinas de ensino da língua, onde se buscou discutir junto com os professores e a comunidade Apurinã em geral métodos para o ensino da sua língua nativa. 
Vale destacar, ainda, a recepção positiva das oficinas de ensino e dos materiais didáticos por parte dos Apurinã, sendo isso possível, sobretudo, por terem sido considerados na elaboração desses materiais aspectos dos usos e das distintas variedades dialetais presente na língua. A elaboração desses materiais para ensino da língua Apurinã se configuram, portanto, como instrumentos importantes para o processo de revitalização do Apurinã, uma vez que a língua portuguesa é usada como L1 na maioria das comunidades.

Concluímos que o sucesso de ações de revitalização linguística e cultural de línguas indígenas dependerá da situação social e histórica em que se encontram essas populações, bem como da luta para a manutenção de sua língua e cultura. Por outro lado, é importante que toda a comunidade de Letras e Linguística do nosso país tenha acesso a estudos sobre essa temática, pois somente com maior interesse será possível dar visibilidade a essas questões.

\section{Referências}

AIKHENVALD, A. Y. Arawak. In: STRAZNY, P. (ed.). Encyclopedia of Linguistics. New York: Fitzroy Dearborn, 2005. p. 81-84.

AUSTIN, P. K. Current issues in languages documentation. In: AUSTIN, P. K. (ed.). Language Documentation and Descripition. v. 7. Londres: SOS, 2010. p. 12-33.

AUSTIN, P. K.; SALLABANK, J. Language endangerment. Cambridge University Press, New York, 2011. 581 p.

CORREAA, G. G. As reformas educacionais brasileiras: programas de ensino em Ciências e seriação escolar. 1997. 201 f. Dissertação (Mestrado em Educação) - Centro de Ciências Humanas e Artes, Universidade Federal de Uberlândia, Uberlândia, 1997. DOI https://doi.org/10.5327/z2176-947820160027.

CUNHA, R. B. Políticas de línguas e educação escolar no Brasil. Educar, n. 32, Curitiba, p. 142-159, 2008. DOI https://doi.org/10.1590/s0104-40602008000200011. 
DALBY, A. Language in Danger: The Loss of Linguistic Diversity and the Threat to our Future. New York, Columbia University Press. 2003. In: DRUDE, S. Documentação Linguística: o formato de anotações de textos. Estudos Linguísticos, XXXV, p. 27-51, 2006.

DRUDE, S. Documentação Linguística: o formato de anotações de textos. Estudos Linguísticos, XXXV, p. 27-51, 2006.

FACUNDES, S. da S. The Apurinã (Arawak) Language of Brazil. SUNY-Buffalo: Tese de Doutorado, 2000, p. 702.

FACUNDES, S. da S.; VIRTANEN, P. K.; FREITAS, M. F. P. de; LIMA-PADOVANI, B. F. S. de; COSTA, P. N. Issues on language revitalization and engagements in the Amazon: The case of Apurinã. In: BRUNN, S. D.; KEHREIN, R. Handbook of the Changing World Language Map. Melbourne: Springer Nature, 2018. DOI https://doi.org/10.1007/978-3-319-73400-2_35-1.

HIMMELMANN, N. P. Language Documentation: What is it and what is it good for? In: GIPPERT, J.; HIMMELMAN, N.; MOSEL, U. (org.). Essentials of Languages Documentation. Berlin: Mouton de Gruyter, 2006. 437 p.

HIMMELMANN, N. P. Documentary and descriptive linguistics. Linguistics, RuhrUniversität Bochum, v. 36, p. 95-161, 1998. DOI https://doi.org/10.1515/ling.1998.36.1.161.

HINTON, L; HALE, K. The Green Book of Language Revitalization in Practice. Academic Press, 2001.

LADEIRA, M. E. De “povos grafos" a "cidadãos analfabetos": as concepções teóricas subjacentes às propostas educacionais para os povos indígenas no Brasil. In: CUNHA, M. C.; CESARINO, P. N. (org.). Políticas culturais e povos indígenas. São Paulo: Unesp, 2016. DOI https://doi.org/10.5380/cra.v19i2.58555.

LIMA-PADOVANI, B. F. S. Levantamento Sociolinguístico do Léxico da Língua Apurinã e sua contribuição para o conhecimento da cultura e história Apurinã (Aruák). Dissertação (Mestrado) - Universidade Federal do Pará, Belém, 2016. f. 192. DOI https://doi.org/10.20873/uft.2179-3948.2019v10n1p161.

MOORE, D.; GABAS, N. J. O Futuro Das Línguas Indígenas Brasileiras. Saturno. DOI https://doi.org/10.28998/0103-6858.2000n25p13-29. 
http://saturno.museu-goeldi.br/lingmpeg/portal/downloads/publicacoes/dennyfutudo-das-linguas-indigenas-brasileiras.pdf. Acesso: 25 abr. 2018.

MOORE, D.; GALUCIO, A. V.; MOORE; GABAS, N. J. Desafio de documentar e preservar línguas. Scientific American Brasil. v. 3, p. 36-43, 2008. Edição Especial.

MOORE, D.; GALUCIO, A. V. Perspectives for the documentation of indigenous language in Brazil. In: BÁEZ, G. P.; ROGERS, C.; LABRADA, J. E. R. (org.). Language Documentation and Revitalization in Latin American Contexts. 1 ed. Berlin: De Gruyter, v. 295, p. 29-58, 2016. DOI https://doi.org/10.1515/9783110428902.

MUFWENE, S. S. The Ecology of Language Evolution. Chicago: Cambridge University Press, University of Chicago, 2001. 274 p.

MÜHLHÄUSLER, P. Assessing the demage: structural and lexical effects. In: Linguistic Ecology: language change and linguistic imperialism in the Pacific region. London; New York: Routledge, 1996. p. 269-310. DOI https://doi.org/10.4324/9780203211281.

RODRIGUES, A. Línguas indígenas brasileiras. Brasília: Laboratório de Línguas Indígenas da UnB, 2013. p. 29. DOI https://doi.org/10.11606/d.18.2010.tde-22122010154505. Disponível em: http://www.laliunb.com.br. Acesso em: 02 mar. 2018.

SCHIFFMAN, H. F. Linguistic culture and Language Policy. London; New York: Routledge, 1996.

SEKI, L. Perspectivas para os estudos linguísticos no Brasil. Boletim da ABRALIN, 12. Campinas: IEL/Unicamp, 1991. p. 7-24.

SEKI, L. A Linguística Indígena no Brasil. Delta, vol. 15, nº Especial, 1999. p. 257-290.

SEKI, L. A linguística Indígena do Brasil. Delta, vol. 15, n. 5, 2009. p. 257-290.

SILVA, W. de L. Apresentação: estudos linguísticos de línguas indígenas brasileiras. ReVEL, 2009. p. 1-8.

SPOLSKY, B. Language Policy. Cambridge: Cambridge University Press, 2004.

WOODBURY, A. C. Language Documentation. In: AUSTIN, P. K.; SALLABANK, J. (org.). Language documentation and archiving. New York: Cambridge University Press, 2011. p. 159-186. DOI https://doi.org/10.1017/cbo9780511975981.009. 